\title{
Ectopic Pituitary Adenoma: Case Report with Review of Literature
}

\author{
Satish Nair ${ }^{1}$ W. V. B. S. Ramalingam ${ }^{2}$ Reena Bharadwaj ${ }^{3} \quad$ Akshat Malik $^{4}$ Rachana Prasad $^{5}$ \\ 1 ENT-HNS, Apollo Hospitals, Bengaluru, Karnataka, India \\ 2 ENT-HNS, BLK Hospital, Delhi, India \\ 3 Department of Pathology, Armed Forces Medical College, \\ Pune, Maharashtra, India \\ ${ }^{4}$ Department of Oncology, TMH, Mumbai, Maharashtra, India \\ ${ }^{5}$ ENT, Command Hospital (EC), Kolkata, West Bengal, India \\ Indian J Neurosurg 2017;6:117-121. \\ Address for correspondence Dr. Satish Nair, MBBS, MS (ENT), \\ Apollo Hospitals, Bengaluru, Karnataka, India \\ (e-mail: aachku@yahoo.com).
}
Abstract
Keywords
- ectopic pituitary adenoma
- sphenoid sinus
- endoscopic excision

Ectopic pituitary adenoma (EPA) is a rare presentation first described by Erdheim. Most of the EPAs described in literature occur in the sphenoid sinus or suprasellar region. We describe a case of an EPA originating from the choana presenting as a case of nasal mass along with detailed literature review.

\section{Introduction}

Pituitary adenomas are benign, slow-growing tumors, which account for $15 \%$ of all intracranial tumors in adults. Ectopic pituitary adenoma (EPA) is a rare presentation first described by Erdheim in 1909. Most of the EPAs described in literature occur in the suprasellar region or the sphenoid sinus. We describe a case of an EPA originating from the choana presenting as a case of nasal mass along with detailed literature review.

\section{Case Report}

A 36-year-old man with a case of solitary osseous plasmacytoma in the left nasal cavity presented to our center after initial treatment with radiotherapy. The initial history showed recurrent epistaxis and nasal obstruction. The biopsy from the lesion was diagnosed as solitary osseous plasmacytoma. The patient underwent 3D CRT (45 Gy/25\#). On follow-up there was no significant change in the size of the lesion, and on further evaluation by nasal endoscopy, a reddish, smooth, polypoidal mass was seen in the posterior part of left nasal cavity with attachment to the sphenoethmoidal recess with the lower part hanging into the nasopharynx (-Fig. 1). Contrast-enhanced computed tomography (CECT) scan revealed a mild enhancing soft tissue lesion in the left sphenoid and nasopharynx with no bone erosion. The sphenopalatine foramen region, pterygopalatine fossa, and sella were normal (-Fig. 2). Positron emission tomography-computed tomography (PET-CT) scan showed a soft tissue density lesion in the left sphenoethmoidal region (SUV 5.3) with extension into left nasal cavity. The bone marrow biopsy and skeletal survey were normal.

The case was discussed in the institutional tumor clinic, and in view of the lesion being well-circumscribed and accessible, endoscopic excision of the lesion was planned. On endoscopic excision the lesion was $3 \times 2 \mathrm{~cm}$ in size (-Fig. 3), and it was found to be attached to the superior part of choana with extension into the left sphenoid sinus and nasopharynx. The roof of sphenoid was found to be normal and the postoperative period was uneventful. Histopathology revealed tumor cells in glands, acini, papillae, trabeculae, cords, and sheets. The cells were monomorphic with plasmacytoid appearance with granular cytoplasm (-Fig. 4). Immunohistochemistry (IHC) revealed positive for synaptophysin, chromogranin, and follicle-stimulating hormone (FSH). IHC was negative for CD 138, luteinizing hormone (LH), adrenocorticotropic received

April 9, 2015

accepted after revision

April 4, 2016

published online

March 14, 2017
DOI https://doi.org/

10.1055/s-0036-1584598. ISSN 2277-954X. (c) 2017 Neurological Surgeons' Society of India
License terms

(요 (1) $\Theta$ 


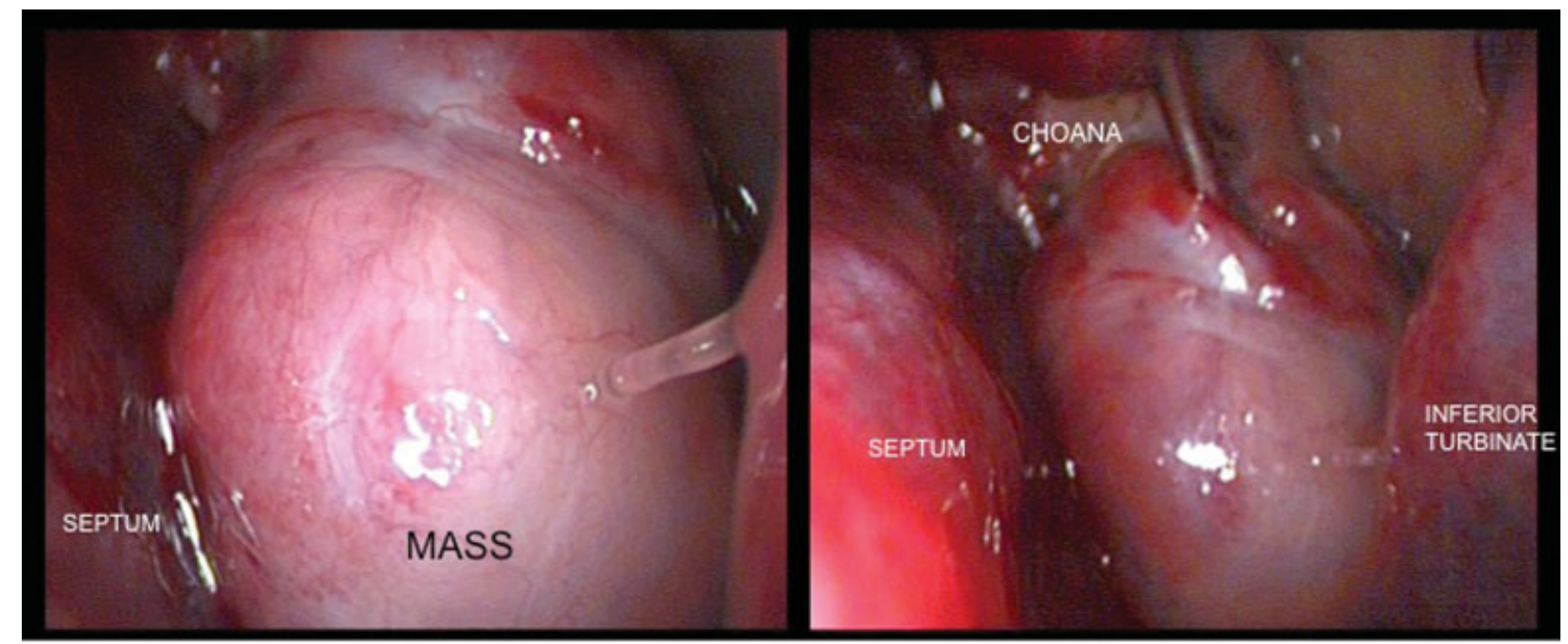

Fig. 1 Endoscopic view of the left nasal cavity.

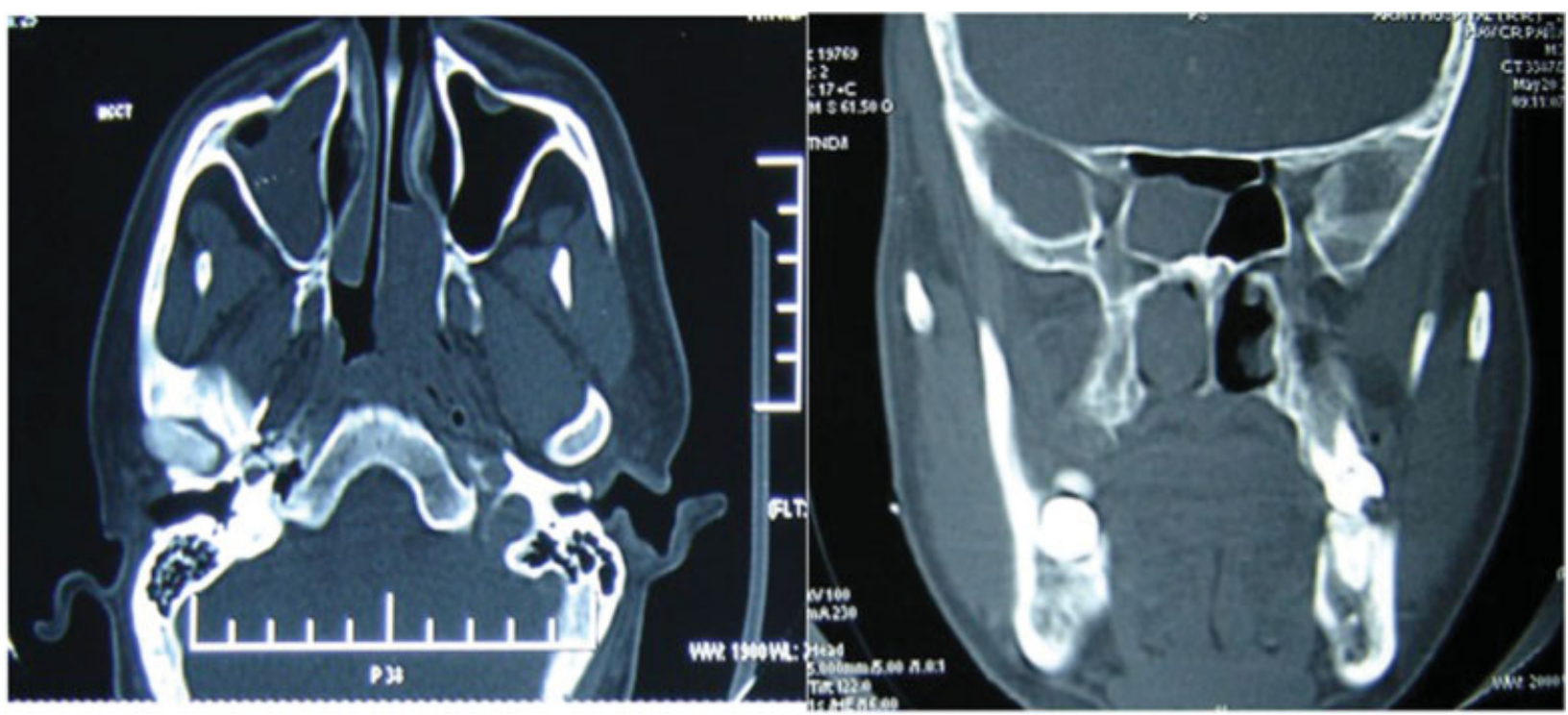

Fig. 2 CT scan reveals a mass in posterior part of nasal cavity and nasopharynx with no bone erosion.

hormone $(\mathrm{ACTH})$, growth hormone $(\mathrm{GH}), \mathrm{S} 100$, smooth muscle actin (SMA), and carcinoembryonic antigen (CEA). Final histopathology with IHC revealed the tumor to be a pituitary adenoma. The hormonal assay revealed normal levels of all pituitary hormones (-Table 1). Postoperative recovery was uneventful, and the patient is on regular follow-up since past 2 years.

\section{Discussion}

Normal pituitary tissue can be present as remnants of Rathke pouch along the craniopharyngeal migration route toward the sellar area. In the suprasellar region normal pituitary cells are found in $75 \%$ of adult brains, and in the pharyngeal roof they may be present as pharyngeal pituitary. ${ }^{1}$

EPAs are rare tumors that occur outside the sella without continuity to normal pituitary gland. Various theories regarding development of EPA are (1) adenoma arising from residual cells of Rathke pouch, persisting along the developmental pathway, and located in the sphenoid sinus or nasopharynx, (2) derived from the cells of the supra diaphragmatic portion of the pituitary stalk located in the suprasellar region, (3) arising from deposits of pituitary cells in the subarachnoid space, which could be implanted during dissemination through cerebrospinal fluid, and (4) derived from aberrant migrating cells of the craniopharyngeal duct in the third ventricle. The diagnosis of EPA is confirmed by distinguishing it from pituitary adenoma extending from the sella turcica by radiologic examinations.

Because of the rarity of the disease and limited review available on the subject in literature, we performed a detailed literature review of all cases of EPA from 1909 to 2010 and found 112 cases, including the present case 




Fig. 3 Excised specimen of the ectopic pituitary adenoma. described (-Table 2). Medline was used with medical subject heading search parameters looking for all available articles of EPA. The data were statistically analyzed it using SPSS Ver 18 (SPSS Inc, Chicago, United States).

EPA is usually seen in the fourth to seventh decades of life with a slight female preponderance. ${ }^{2,3}$ In the literature review, the incidence in females (54.3\%) was found to be significantly higher than in males (45.7\%). The age of the patients ranged from 6 to 80 years with mean age at diagnosis being 45 . Among the males the mean age was 46 as compared with 43 in females. Males at the time of diagnosis were younger than females, which were found to be statistically significant $(p<0.05)$.

EPAs are usually seen in the sphenoid sinus or suprasellar region with other less common sites such as the clivus, cavernous sinus, nasopharynx, nasal cavity, petrous and temporal bone, sphenoid bone, mid-nasal duct, third ventricle, and left temporal lobe. ${ }^{3-6}$ On review, EPA was commonly seen in the sphenoid sinus (34.5\%), followed by suprasellar region (20.4\%) and clivus (16.8\%) (-Table 3).

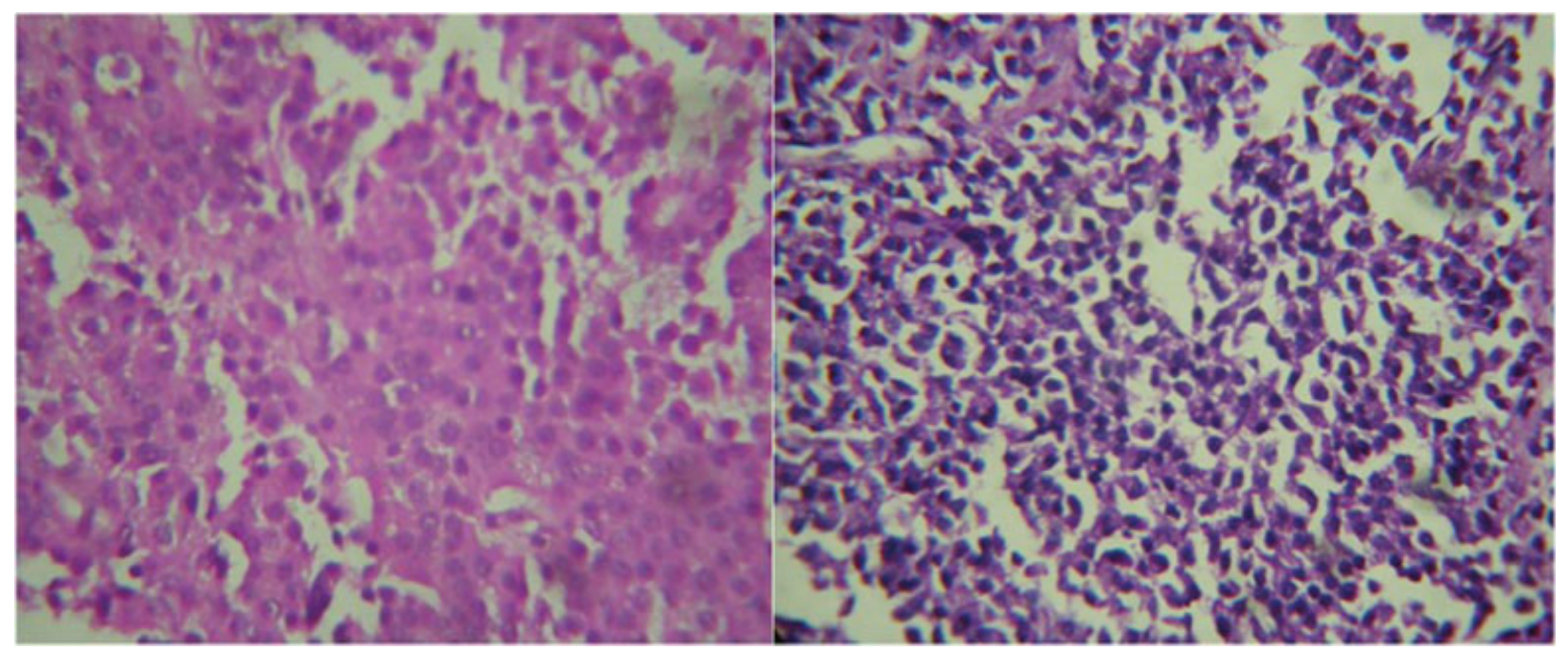

Fig. 4 Histopathology showing monomorphic tumor cells with plasmacytoid appearance with granular cytoplasm.

Table 1 Hormonal status of the patient

\begin{tabular}{|l|l|l|}
\hline Hormone & Levels & Reference values \\
\hline TSH $(\mu \mathrm{lU} / \mathrm{mL})$ & $1.71 \mu \mathrm{lU} / \mathrm{mL}$ & $0.5-6.5$ \\
\hline $\mathrm{LH}(\mathrm{IU} / \mathrm{L})$ & $8.21 \mathrm{IU} / \mathrm{L}$ & $2.5-9.8(\mathrm{AM})$ \\
\hline $\mathrm{FSH}(\mathrm{IU} / \mathrm{L})$ & $10.89 \mathrm{IU} / \mathrm{L}$ & $1-12(\mathrm{AM})$ \\
\hline $\mathrm{PRL}(\mathrm{ng} / \mathrm{mL})$ & $12 \mathrm{ng} / \mathrm{mL}$ & $<25$ (adults) \\
\hline Cortisol $(\mathrm{ugm} / \mathrm{dL})($ basal) & $7.34 \mathrm{ug} / \mathrm{mL}$ & $12-25$ \\
\hline Cortisol $(\mathrm{ug} / \mathrm{mL})($ post-ACTH) & $20.01 \mathrm{ug} / \mathrm{mL}$ & $>18$ \\
\hline Testosterone $(\mathrm{ng} / \mathrm{mL})$ & $4.12 \mathrm{ng} / \mathrm{mL}$ & $3-12($ AM) \\
\hline
\end{tabular}

Abbreviations: ACTH, adrenocorticotropic hormone; AM, adult male; FSH, follicle-stimulating hormone; LH, luteinizing hormone; PRL, prolactin; $\mathrm{TSH}$, thyroid-stimulating hormone. 
Table 2 Literature review with distribution of EPA as per location and hormonal status

\begin{tabular}{|c|c|c|c|c|c|c|c|c|c|}
\hline \multirow[t]{2}{*}{ Hormone } & \multicolumn{9}{|l|}{ Location } \\
\hline & Sphenoid & Suprasellar & Clivus & Cavernous sinus & Nasopharynx & Parasellar & Nasal & Others & Total \\
\hline ACTH & 13 & 9 & & 6 & 2 & 3 & 1 & 1 & 35 \\
\hline $\mathrm{GH}$ & 6 & 1 & 2 & & & & & 1 & 10 \\
\hline PRL & 12 & 6 & 9 & & & 1 & & 1 & 29 \\
\hline TSH & & & & & 1 & & & 1 & 2 \\
\hline $\mathrm{LH}$ & & & & & & & & 1 & 1 \\
\hline FSH & & & & & 1 & & & & 1 \\
\hline Inactive & 9 & 7 & 8 & 1 & 4 & & 2 & 3 & 34 \\
\hline & 40 & 23 & 19 & 7 & 8 & 4 & 3 & 8 & 112 \\
\hline
\end{tabular}

Abbreviations: ACTH, adrenocorticotropic hormone; EPA, ectopic pituitary adenoma; FSH, follicle-stimulating hormone; $\mathrm{GH}$, growth hormone; LH, luteinizing hormone; PRL, prolactin; TSH, thyroid-stimulating hormone.

Table 3 Prevalence of EPA as per location in literature

\begin{tabular}{|l|l|l|}
\hline Location & Number & Percentage \\
\hline Sphenoid & 40 & 35.71 \\
\hline Suprasellar & 23 & 20.40 \\
\hline Clivus & 19 & 16.80 \\
\hline Cavernous sinus & 7 & 6.25 \\
\hline Nasopharynx & 8 & 7.10 \\
\hline Parasellar & 4 & 3.50 \\
\hline Nasal & 3 & 2.70 \\
\hline Others & 8 & 7.10 \\
\hline
\end{tabular}

Abbreviation: EPA, ectopic pituitary adenoma.

The clinical features of EPA depend on the hormonal activity of the ectopic pituitary tissue or the pressure effects caused by the lesion. ${ }^{7,8}$ Among the common symptoms include headache, nasal blockage, epistaxis, decrease in vision due to pressure on the chiasma, and cerebrospinal leak. Majority (68.3\%) of the EPA are hormonally active with patients of hormonally active tumor (mean age 42.5) diagnosed at a significantly younger age as compared with inactive disease (mean age 51.3). Though females (74\%) were found to have higher active tumors as compared with males (64.2\%), sex was not found to be a statistically significant risk factor $(p=0.313)$. The most common hormone secreted by the EPA was adrenocorticotrophic hormone $(31.3 \%)$, followed by prolactin $(25 \%)$ and $\mathrm{GH}$ (8.9\%). Moreover, $30.7 \%$ of patients had silent or inactive tumor as was seen in our case ( - Table 4 ).

EPA due to its varied location and about one-third being hormonally inactive proves to be a difficult entity to diagnose. It needs to be differentiated from other sphenoidal and central skull base lesions such as chronic sinusitis, chordoma, craniopharyngioma, plasmacytoma, lymphoma, melanoma, metastasis, and fungal infection of sphenoid sinus. Radiologic investigation by CT scan and magnetic resonance imaging (MRI) provide valuable
Table 4 Prevalence of EPA as per hormonal status in literature

\begin{tabular}{|l|l|l|}
\hline Hormone & Number & Percentage \\
\hline ACTH & 35 & 31.30 \\
\hline GH & 10 & 8.90 \\
\hline PRL & 29 & 25.89 \\
\hline TSH & 2 & 1.80 \\
\hline LH & 1 & 0.90 \\
\hline FSH & 1 & 0.90 \\
\hline Inactive & 34 & 30.40 \\
\hline
\end{tabular}

Abbreviations: ACTH, adrenocorticotropic hormone; EPA, ectopic pituitary adenoma; $\mathrm{FSH}$, follicle-stimulating hormone; $\mathrm{GH}$, growth hormone; LH, luteinizing hormone; PRL, prolactin; TSH, thyroidstimulating hormone.

information on the origin, extent of the tumor, and, importantly, surgical approach. On CT scan they are usually isointense relative to adjacent gray matter, and show moderate enhancement, whereas on MRI they are heterogeneous, with foci of low signal intensity on T1WI and high signal intensity on T2WI. ${ }^{9,10}$

The mainstay of treatment is surgical excision, which can be performed by endoscopic or open method depending on the location of the lesion with postoperative radiotherapy reserved for inoperative or residual disease. In cases with hormonally active tumor pharmacologic treatment also acts complementary to surgery. Malignant transformation is rare and one case has been described in literature. ${ }^{11}$

\section{References}

1 Thompson LD, Seethala RR, Müller S. Ectopic sphenoid sinus pituitary adenoma (ESSPA) with normal anterior pituitary gland: a clinicopathologic and immunophenotypic study of 32 cases with a comprehensive review of the English literature. Head Neck Pathol 2012;6(1):75-100

2 Suzuki J, Otsuka F, Ogura T, et al. An aberrant ACTH-producing ectopic pituitary adenoma in the sphenoid sinus. Endocr J 2004; 51(1):97-103 
3 Hou L, Harshbarger T, Herrick MK, Tse V. Suprasellar adrenocorticotropic hormone-secreting ectopic pituitary adenoma: case report and literature review. Neurosurgery 2002;50(3):618-625

4 Anand VK, Osborne CM, Harkey HL III. Infiltrative clival pituitary adenoma of ectopic origin. Otolaryngol Head Neck Surg 1993; 108(2):178-183

5 Peker S, Sun I, Kurtkaya-Yapicier O, Elmaci I, Pamir MN. Ectopic pituitary adenoma located at the pituitary stalk. Case report. J Neurosurg Sci 2005;49(1):25-29

6 Tovi F, Hirsch M, Sacks M, Leiberman A. Ectopic pituitary adenoma of the sphenoid sinus: report of a case and review of the literature. Head Neck 1990;12(3):264-268
7 Langford L, Batsakis JG. Pituitary gland involvement of the sinonasal tract. Ann Otol Rhinol Laryngol 1995;104(2):167-169

8 Bhatoe HS, Kotwal N, Badwal S. Clival pituitary adenoma with acromegaly: case report and review of literature. Skull Base 2007;17(4):265-268

9 Slonim SM, Haykal HA, Cushing GW, Freidberg SR, Lee AK. MRI appearances of an ectopic pituitary adenoma: case report and review of the literature. Neuroradiology 1993;35(7):546-548

10 Das CJ, Seith A, Gamanagatti S, Goswami R. On the AJR viewbox. Ectopic pituitary adenoma with an empty sella. AJR Am J Roentgenol 2006;186(5):1468-1469

11 Hosaka N, Kitajiri S, Hiraumi H, et al. Ectopic pituitary adenoma with malignant transformation. Am J Surg Pathol 2002;26(8):1078-1082 